\title{
Pedagogical Considerations for Technology-Enhanced Learning
}

\author{
Linda Daniela $\mathbb{B}$
}

\begin{abstract}
Technology-enhanced learning is a term often used in discussions about the place and role of technology in education. Yet many gaps still need to be addressed from a pedagogical perspective to remove the veil of fascination from technology-enhanced learning and to ensure that its use is planned purposefully. Planning should take account of the intended uses of the technology, which may be multifold. This paper summarizes the pedagogical considerations for a technologyenhanced learning process. In fact it is often thought that introducing technology to the educational environment is sufficient, without specifically restructuring the pedagogical process. The paper analyzes the potential goals of using technology in the educational process. It also looks at the pedagogical factors that make technologyenhanced learning successful: learning motivation, cognitive development, cognitive load, and knowledge development in the discourse of technology-enhanced learning. The chapter is organized as follows: an introduction to the terms followed by two sections- "Technology-enhanced learning" and "Pedagogical considerations"—and a discussion.
\end{abstract}

Keywords Technology-enhanced learning $\cdot$ Pedagogical considerations $\cdot$ Smart pedagogy $\cdot$ Cognitive load $\cdot$ Cognitive development $\cdot$ Knowledge assessment

\section{Introduction}

As technologies develop, some inevitably enter the field of education, and the tasks of the education system to incorporate them successfully are multifold:

- Learning to use technology to support the knowledge acquisition process, to solve certain tasks, and to make some activities more efficient;

\section{Daniela $(\varangle)$}

University of Latvia, Riga 1586, LV, Latvia

e-mail: linda.daniela@lu.lv 
- Learning to use technology to get access to knowledge that is only available in certain places and at certain times, owing to distance or environmental barriers, language barriers, or special needs barriers;

- Learning the principles of developing new technologies and creatively finding new solutions where technology serves as a tool for creating innovations;

- Using Smart pedagogical principles regarding the sequencing of the learning process, the interrelationships of learning motivation and learning achievements, the interrelationships of cognitive load and cognitive development, the regularities of human development, and the interrelationships of the opportunities and challenges created by technology (Daniela 2019);

- Evaluating learning achievements, taking account of different dimensions of knowledge assessment (Daniela 2020, 2021).

In this chapter, the term technology refers to the various digital technologies and technological solutions used in the educational environment. The advent of digital solutions marked a new turning point in computer technology, from its triumphant beginnings in 1971 in Santa Clara, California, when Intel introduced its microprocessor (Chan et al. 2006). The term digital teaching materials means any technological (digital) solution that provides necessary learning content. The term educators is used for all levels of education and can refer to a teacher in pre-school, general education, or higher education. The term student is used generically to describe any person who is learning something.

There is a lot of talk about the fact that technology creates many new opportunities. At the same time, numerous claims are made that technology alone has not made any new or unexpected progress in education, and that the process itself still needs to be purposeful for learning to take place. Thus, educators plan and organize technology-enhanced learning, but to do so requires a certain knowledge of the pedagogical regularities of a technology-enhanced learning process, and also certain skills in the use of technology and digital learning tools. The same applies to students and their knowledge and skills of technology and digital learning tools. In the absence of such knowledge, technology's potential is not fully exploited. This is because a negative attitude forms towards those who agree with the developers of the Technology Acceptance Model: in addition to technological factors, affective aspects, such as perceived usefulness, are important for the use of technology (Davis 1986, 1989). Moreover, it is important to bear in mind that knowledge can be assessed from (i) knowledge growth perspectives, (ii) knowledge acquisition perspectives, (iii) perspectives on knowledge accumulation, and (iv) perspectives on access to knowledge (Daniela 2020). 


\section{Technology-Enhanced Learning}

The term technology-enhanced learning is not new or unknown in the field of education. It has its roots in terms such as computer-supported collaborative learning (Stahl 2006), computer-assisted instruction, computer-aided instruction, computerbased learning, and computer-mediated learning, which are regarded as synonyms (De Bruyckere and Kirschner 2019), and information and communication technology for education (Usluel et al. 2008). Later, in discussions on their impact on the learning process, questions were asked about the use of technologies and whether they improve learning outcomes or, conversely, whether they negatively affect learning outcomes (Kirkwood and Price 2014).

The use of technology can have several objectives, which can all be related to technology-enhanced learning and can also complement each other (see Fig. 1). In order to evaluate the successes or failures of such a process, it is important to be aware of the key objectives in each case. These learning objectives can be divided as follows:

(1) Various technologies are used as tools for face-to-face learning to speed up certain activities, such as preparing material, printing it, drafting presentations for display on screen, or showing students technologies and how to use them. Technology can also be used to make certain processes, such as drawing, more efficient and accurate. It can speed up the flow of information through the Internet, Bluetooth, or similar information transmission systems. For example, if a computer is only used for printing study materials, making spreadsheets, or preparing presentations, then the acquisition of certain skills should be the

Fig. 1 Objectives for the use of technologies

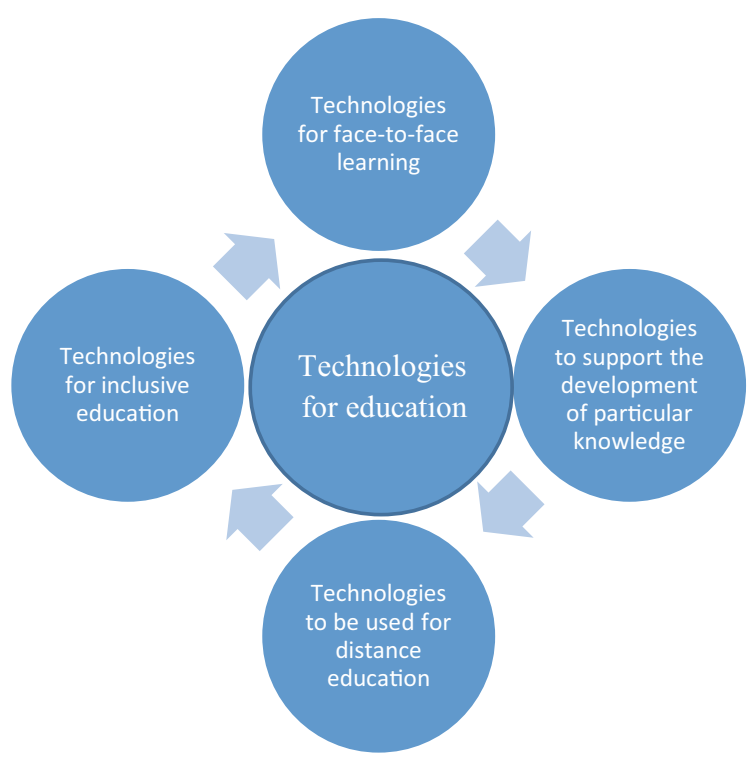


parameter used for analyzing increased knowledge. If a computer, 3D printer, or robotics kits is used to develop specific knowledge, such as the ability to program, the ability to perform accurate calculations for programming a robot, or the ability to analyze the results achieved, then increases in knowledge in a certain segment can be assessed and analyzed in terms of specific knowledge growth.

(2) We can analyze whether the activities achieved the learning objective, and this can be formulated as follows: technologies are used for the development of knowledge (all dimensions of knowledge).

(3) Another important goal is that technologies ensure learning anywhere, anytime, which can be useful for synchronous and asynchronous learning processes. In such cases, access to knowledge may also take place outside the formal education environment or it may not be available because a particular historical period is over or a certain cultural and historical value is no longer current. Other technological solutions translate material in foreign languages, enabling students to understand it. Teachers might use such solutions to deliver remote lessons to students who are unable to attend the educational institution for some reason at a given time. They might also be for a visit to a virtual museum, or access to knowledge that is not normally available, such as viewing the internal organs of humans, etc.

Despite the wide range of opportunities offered by technology and the different educational goals, one broad area that needs to be addressed is technologies for inclusive education. In this area, the technologies already in use should be evaluated in terms of their usability with students with special needs; for example, can students participate in robotics activities if they have vision problems? Can they grab and connect small parts if they have muscle weakness? Or can they watch bright videos on an interactive whiteboard if they are sensitive to bright colors? Thus, if the aim is to make classroom technologies available for use with and by all students, it is important to be aware of all students' abilities to avoid social exclusion. In such cases, the teacher may consider using assistive technology to provide equal opportunities for all students.

Technology-enhanced forms of learning can be: (a) technology as a support tool during face-to-face learning (e.g., computer, printer, 3D printer, etc.) helping students perform certain tasks; (b) technology as a learning tool for acquiring specific knowledge (e.g., educational robotics kits, computer simulations for mastering computational thinking); (c) technology that can provide learning opportunities anywhere, anytime (e.g., learning platforms, educational applications); and (d) technology for inclusive education that can support learning (e.g., assistive technology that can read out text to people who cannot read it themselves or simulate a classroom when a student cannot attend in person, etc.). 


\section{Pedagogical Considerations}

When planning and organizing a technology-enhanced learning process, the principles of Smart pedagogy should be taken into account (Daniela 2019, 2020; Borawska-Kalbarczyk et al. 2019). It is also important to analyze the digital competence of both teachers (Biezā 2020) and students (Černochová et al. 2018) so that technology-enhanced learning can take place.

Everyone involved in the learning process considers how cognitive development can be supported. Promoting the development of cognitive processes-perception, sensation, attention, thinking, imagination, memory, creative thinking and problem-solving - requires knowledge of the regularities of human cognitive development, which have been discussed by various authors (Piaget and Cook 1952; Vygotsky 1978; Erikson, 1950). We can analyze learning from the perspective of Bloom's taxonomy (Bloom et al. 1956; Anderson et al. 2001), where the first stage is remembering, followed by understanding, applying, analyzing, evaluating, and creating. Thus, in a technology-enhanced learning process, depending on which of the technology use objectives (see Fig. 1) we emphasize, we need to ensure that students remember the information they have learned, understand the meaning of this information, are able to use it, can analyze what is happening, process and evaluate it, and create something new. But all this must be looked at in terms of age development, because young children are able to remember fewer items of information than older children. As they grow, their cognitive capacity increases: they are able to retain more information, create cognitive patterns, and use their thinking processes to generate new ideas. In general, this is a logical learning process, where teachers promote the step-by-step development of these cognitive processes. What changes in technology-enhanced learning, once it is clear to everyone that learning is a natural process in which a person's cognitive abilities develop gradually? One answer could be a person's ability to focus, because she has to be able to remember information, use it, analyze it, and so on. It is often assumed that technology is interesting and that students will apply this interest to acquire new knowledge and generate new ideas. In general, the concept of an 'interesting learning process' can certainly drive learning, but interest can also affect the ability to focus.

Here is an example. If a student works on a task and focuses all his attention on it in order to solve it, and he succeeds, thereby building satisfaction in his accomplishment, then his motivation to learn and achieve grows even more. If the task assigned to the student has a degree of complexity that requires a cognitive load from him, then it could turn out in one of several ways:

(a) The student will think more intensely and will look for additional information to solve the task, because he has developed learning motivation and the ability to focus, even when additional cognitive load is needed;

(b) The student will decide that it is too complicated and will look for new interesting stimuli, thus avoiding cognitive load. This could affect how much new information is learned and how much information can then be used in cognitive processes to generate new ideas. The student's previous knowledge, his 
motivation to overcome difficulties and the specifics of the proposed task will determine whether he will try to connect this cognitive load to finding a solution to a more complex task.

Thus, while it is important to consider age-appropriate and goal-oriented tasks, it is also necessary to tailor the design of technology-based tasks to ensure the student directs this cognitive load towards solving them. Otherwise, he might avoid the cognitive load and instead choose to use technology for other purposes, such as scrolling through social media or playing games, which do not take him any closer to achieving the set learning goal. Technology can stimulate interest in new learning content by enabling users to see things differently, access information faster, and so on. At the same time, technology can be opaque. For example, understanding how to get access to information or the design of the technology can add a considerable cognitive burden. Sometimes design solutions are ill-considered, which again creates an additional cognitive load that affects learning processes. In a technology-enhanced environment, students can easily switch the focus of their attention.

This leads us to the concept of cognitive load, which can be categorized as: intrinsic, germane, and extraneous (Sweller et al. 1998). A person's cognitive load depends on the capacity of her working memory. Intrinsic cognitive load is a person's capacity to process information. It is affected by how much a person has mastered and what information she is able to analyze. Germane cognitive load is the way a person forms thought patterns to make it easier for her to learn information, which is an essential prerequisite for learning. Extraneous cognitive load depends on the way information is presented and is directly related to information architecture and technology design.

In addition to giving students access to information, it is also important to organize it in such a way that learning can take place. For example, if we want students to learn something new that requires intrinsic cognitive load, we need to recognize that they will have to incorporate this new knowledge into their existing schemas and create new knowledge schemas (germane cognitive load will be at work here). For this to happen, the educator's task is to ensure that students are not subjected to large amounts of extraneous load during the learning process (i.e., lots of unimportant information, lots of small details, information presented chaotically, etc.). This distracts them from the essentials and creates an unnecessary cognitive load, which hinders the acquisition of new knowledge.

This means that, in a technology-enhanced learning environment, information architecture is as important as the content students have to learn. There should be no extraneous cognitive load on the student, so she can use her prior knowledge of the content both to perform a specific task and to find new information. To summarize the information analyzed in this chapter, the following are important for the organization of a technology-enhanced learning process:

(1) whether technology is perceived as being useful for acquiring knowledge or for providing access to knowledge; 
(2) whether students and teachers have the appropriate digital competence to use technology, which in turn affects the extent to which the opportunities created by technology will be used in the learning process;

(3) the design of digital learning materials, which should provide an opportunity for acquiring new knowledge, while not creating an extraneous cognitive load, to ensure a context in which new knowledge is acquired;

(4) learning motivation, which depends on prior knowledge, interest, and the feedback students receive.

\section{References}

Anderson, L.W., Krathwohl, D.R., Airasian, P.W., Cruikshank, K.A., Mayer, R.E., Pintrich, P.R., Raths, J., Wittrock, M.C.: A taxonomy for learning, teaching, and assessing: a revision of Bloom's taxonomy of educational objectives. Longman, New York (2001)

Biezā, K.E.: Digital literacy: concept and definition. Int. J. Smart Educ. Urban Soc. (IJSEUS) 11(2), $1-15(2020)$

Bloom, B.S., Engelhart, M.D., Furst, E.J., Hill, W.H., Krathwohl, D.R.: Taxonomy of Educational Objectives: The Classification of Educational Goals. Handbook I: Cognitive Domain. David McKay Company, New York (1956)

Borawska-Kalbarczyk, K., Tołwińska, B., Korzeniecka-Bondar, A.: From smart teaching to smart learning in the fast-changing digital world. In: Daniela, L. (ed.) Didactics of smart pedagogy: smart pedagogy for technology enhanced learning, pp. 23-40. Springer, Cham (2019)

Černochová, M., Voňková, H., Śtípek, J., Černá, P.: How do learners perceive and evaluate their digital skills? Int. J. Smart Educ. Urban Soc. 9(1), 37-47 (2018)

Chan, T.W., Roschelle, J., Hsi, S., Sharples, M., Brown, T., Patton, C., et al.: One-to-one technologyenhanced learning: an opportunity for global research collaboration. Res. Pract. Technol. Enhanc. Learn. 1(1), 3-29 (2006)

Daniela, L.: Smart pedagogy for technology enhanced learning. In: Daniela, L. (ed.) Didactics of Smart Pedagogy: Smart Pedagogy for technology Enhanced Learning, pp. 3-22. Springer, Cham (2019)

Daniela, L.: The concept of smart pedagogy for learning in the digital world. In: Daniela, L. (ed.) Epistemological Approaches to Digital Learning in Educational Contexts, pp. 1-16. Routledge, Abingdon (2020)

Daniela, L.: Smart pedagogy as a driving wheel for technology-enhanced learning. Techol. Knowl. Learn. (2021). https://doi.org/10.1007/s10758-021-09536-z

Davis, F.D.: A technology acceptance model for empirically testing new end-user information systems: theory and results. Unpublished doctoral dissertation. MIT Sloan School of Management, Cambridge, MA (1986)

Davis, F.D.: Perceived usefulness, perceived ease of use, and user acceptance of information technology. MIS Q. 13(3), 319-339 (1989)

De Bruyckere, P., Kirschner, P.A.: Computer-assisted learning. In: Tatnall, A. (ed.) Encyclopedia of Education and Information Technologies. Springer, Cham (2019)

Erikson, E.H.: Childhood and society. Norton, New York (1950)

Kirkwood, A., Price, L.: Technology-enhanced learning and teaching in higher education: what is 'enhanced' and how do we know? A critical literature review. Learn. Media Technol. 39(1), 6-36 (2014)

Piaget, J., Cook, M.T.: The origins of intelligence in children. International University Press, New York (1952) 
Stahl, G.: Group cognition: computer support for building collaborative knowledge. MIT Press, Cambridge, MA (2006)

Sweller, J., van Merrienboer, J.J.G., Paas, F.G.W.C.: Cognitive architecture and instructional design. Educ. Psychol. Rev. 10(3), 251-296 (1998)

Usluel, Y.K., Askar, P., Bas, T.: A structural equation model for ICT usage in higher education. J. Educ. Technol. Soc. 11, 262-273 (2008)

Vygotsky, L.S.: Mind in society: the development of higher psychological processes. Harvard University Press, Cambridge, MA (1978)

Open Access This chapter is licensed under the terms of the Creative Commons Attribution 4.0 International License (http://creativecommons.org/licenses/by/4.0/), which permits use, sharing, adaptation, distribution and reproduction in any medium or format, as long as you give appropriate credit to the original author(s) and the source, provide a link to the Creative Commons license and indicate if changes were made.

The images or other third party material in this chapter are included in the chapter's Creative Commons license, unless indicated otherwise in a credit line to the material. If material is not included in the chapter's Creative Commons license and your intended use is not permitted by statutory regulation or exceeds the permitted use, you will need to obtain permission directly from the copyright holder. 